\title{
Differential integrin activity mediated by platelet collagen receptor engagement under flow conditions
}

\author{
Nicholas Pugh'1,2; Ben D. Maddox'; Dominique Bihan'; Kirk A. Taylor²; Martyn P. Mahaut-Smith³; Richard W. Farndale ${ }^{1}$ \\ 'Department of Biochemistry, University of Cambridge, Cambridge, UK; ${ }^{2}$ Department of Biomedical and Forensic Sciences, Anglia Ruskin University, Cambridge, UK; ${ }^{3}$ Department of \\ Molecular and Cell Biology, University of Leicester, Leicester, UK
}

\begin{abstract}
Summary
The platelet receptors glycoprotein $(\mathrm{Gp}) \mathrm{VI}$, integrin $\alpha_{2} \beta_{1}$ and $\mathrm{Gplb} / \mathrm{V} / \mathrm{IX}$ mediate platelet adhesion and activation during thrombogenesis. Increases of intracellular $\mathrm{Ca}^{2+}\left(\left[\mathrm{Ca}^{2+}\right]_{i}\right)$ are key signals during platelet activation; however, their relative importance in coupling different collagen receptors to functional responses under shear conditions remains unclear. To study shear-dependent, receptor-specific platelet responses, we used collagen or combinations of receptor-specific collagen-mimetic peptides as substrates for platelet adhesion and activation in whole human blood under arterial flow conditions and compared real-time and endpoint parameters of thrombus formation alongside $\left[\mathrm{Ca}^{2+}\right]_{\mathrm{i}}$ measurements using confocal imaging. All three collagen receptors coupled to $\left[\mathrm{Ca}^{2+}\right]_{i}$ signals, but these varied in amplitude and temporal pattern alongside variable integrin activation. $\mathrm{GpVI}$
\end{abstract}

engagement produced large, sustained $\left[\mathrm{Ca}^{2+}\right]_{i}$ signals leading to realtime increases in integrins $\alpha_{2} \beta_{1}$ - and $\alpha_{\| b} \beta_{3}$-mediated platelet adhesion. $\alpha_{11 b} \beta_{3}$-dependent platelet aggregation was dependent on $P_{2} Y_{12}$ signalling. Co-engagement of $\alpha_{2} \beta_{1}$ and Gplb/V/IX generated transient $\left[\mathrm{Ca}^{2+}\right]_{i}$ spikes and low amplitude $\left[\mathrm{Ca}^{2+}\right]_{i}$ responses that potentiated GpVI-dependent $\left[\mathrm{Ca}^{2+}\right]_{i}$ signalling. Therefore $\alpha_{2} \beta_{1}, \mathrm{Gplb} / \mathrm{V} / \mathrm{IX}$ and GpVI synergise to generate $\left[\mathrm{Ca}^{2+}\right]_{i}$ signals that regulate platelet behaviour and thrombus formation. Antagonism of secondary signalling pathways reveals distinct, separate roles for $\alpha_{\| b} \beta_{3}$ in stable platelet adhesion and aggregation.

\section{Keywords}

Platelet glycoproteins, collagen receptors, signal transduction, thrombosis, fluid shear

Financial support:

This work was funded by British Heart Foundation grants to NP (Project PG/14/47/30912) and RWF (Programme RG/09/003/27122).

Received: December 5, 2016

Accepted after major revision: April 22, 2017

Epub ahead of print: May 24, 2017

https://doi.org/10.1160/TH16-12-0906

Thromb Haemost 2017; 117: 1588-1600

Supplementary Material to this article is available online at www.thrombosis-online.com

\section{Introduction}

Synergism between collagen receptors mediates platelet adhesion and activation leading to thrombus formation under shear conditions (1). Primary platelet adhesion to collagen occurs via von Willebrand factor (VWF) and the platelet receptor GpIb/V/IX. This interaction is transient, but allows for subsequent engagement of the platelet collagen receptors $\alpha_{2} \beta_{1}$ and GpVI. These mediate firm platelet adhesion and signalling events leading to $\alpha_{\mathrm{II}} \beta_{3}$ activation $(2,3)$. The roles of the different collagen receptors in platelet adhesion and activation under static and flow conditions has been studied using synthetic ligand-mimetic collagen-derived peptides $(1,4-8)$. Recently, we demonstrated that collagendependent platelet activation leading to full thrombus formation at arteriolar shear $\left(1,000 \mathrm{~s}^{-1}\right)$ is dependent on GpVI engagement, with $\alpha_{2} \beta_{1}$ and $\mathrm{GpIb} / \mathrm{V} / \mathrm{IX}$ contributing little to this process (1). However, dynamic aspects of platelet behaviour and the underlying intracellular signalling processes contributing to platelet activation were not investigated.
Increases of $\left[\mathrm{Ca}^{2+}\right]_{\mathrm{i}}$ couple receptor engagement to downstream functional events $(9-11)$. Following platelet activation, $\mathrm{Ca}^{2+}$ is either released from intracellular $\mathrm{Ca}^{2+}$ stores, mainly via inositol trisphosphate $\left(\mathrm{IP}_{3}\right)$ receptors located on the dense tubular system, or enters from the extracellular medium via plasma membrane $\mathrm{Ca}^{2+}$ channels. Whole blood perfusion studies have previously investigated the effect of shear forces on platelet $\left[\mathrm{Ca}^{2+}\right]_{i}$ oscillations upon adhesion to collagen, VWF or fibrinogen $(6,12-20)$. Roles have been identified for GpIb/V/IX and $\alpha_{\mathrm{IIb}} \beta_{3}$ in $\left[\mathrm{Ca}^{2+}\right]_{\mathrm{i}}$ responses via association with VWF A1 and RGD domains, respectively $(12-14,16,17)$. Additionally, different collagen subtypes have been utilised to isolate the relationship between specific collagen receptors during $\left[\mathrm{Ca}^{2+}\right]_{\mathrm{i}}$ responses (20). Engagement of $\alpha_{2} \beta_{1}$ generates a transient $\left[\mathrm{Ca}^{2+}\right]_{\mathrm{i}}$ rise that serves as a pre-requisite to sustained signalling via GpVI (20). However, these experiments were performed at low shear rates $\left(250 \mathrm{~s}^{-1}\right)$ and therefore did not report the role of the $\mathrm{GpIb} / \mathrm{V} / \mathrm{IX} / \mathrm{VWF}$ axis, which is more significant at higher shear rates $(12,21-23)$. Thus the relative contributions of the dif- 
ferent collagen receptors to calcium signalling under arterial shear conditions remain unstudied.

Here, we describe the use of collagen-mimetic peptides and platelet inhibitory reagents to investigate shear-induced platelet collagen receptor engagement and subsequent $\left[\mathrm{Ca}^{2+}\right]_{i}$ oscillations during stable platelet adhesion and thrombus formation. Using image analysis techniques, we further elucidate the effect of receptor-specific engagement on the up-regulation $\alpha_{\mathrm{II}} \beta_{3}(24)$. This represents the first study to correlate and quantify platelet calcium signals that result from collagen receptor-mediated adhesion under physiological flow conditions.

\section{Materials and methods}

Ethical approval for this study was obtained from the Cambridge Human Biology Research Ethics Committee. Collagen-mimetic peptides used in these experiments include the GpVI ligand, the collagen-related peptide, CRP: GCO $(\mathrm{GPO})_{10} \mathrm{GCOG}$-amide (where $\mathrm{O}$ indicates hydroxyproline), the $\alpha_{2} \beta_{1}$-specific peptide, GFOGER: GPC(GPP) $)_{5}$ GFOGER(GPP) $)_{5}$ GPC-amide, the VWF-binding peptide, VWF-III: GPC(GPP) $)_{5}$ GPRGQOGVMGFO-(GPP) $)_{5}$ GPCamide and the inert control peptide, $\mathrm{GPP}_{10}$ : GPC(GPP) ${ }_{10}$ GPCGamide. Bovine tendon type I collagen fibres were from Ethicon Corporation (Somerville NJ, USA). The RGD-mimetic inhibitor of integrin $\alpha_{\text {IIb }} \beta_{3}, \quad$ GR144053, (4-[4-[4-(aminoiminomethyl)phenyl]-1-piperazinyl]-1-piperidineacetic acid trihydrochloride hydrate) was from Novabiochem (Watford, UK). NF449 (4,4,4",4"'-[Carbonylbis(imino-5,1,3-benzenetriyl-bis(carbonylimino))] tetrakis-1,3-benzenedisulfonic acid, octasodium salt, $\mathrm{P}_{2} \mathrm{X}_{1}$ receptor antagonist), 2-MeSAMP (2-Methylthioadenosine 5'-monophosphate triethylammonium salt hydrate, P2Y12 receptor antagonist) and MRS2179 (2'-Deoxy-N6-methyladenosine 3,'5'-bisphosphate tetrasodium salt $\mathrm{P} 2 \mathrm{Y} 1$ receptor antagonist) were from Tocris (Bristol, UK). 5-5'-Dimethyl-BAPTA AM (DMBAPTA) was from Cambridge Bioscience (Cambridge, UK). Before use, the cyclooxygenase inhibitor, acetylsalicylic acid (aspirin; Sigma-Aldrich, Dorset, UK) was diluted to $50 \mathrm{mM}$ in calcium-free Tyrode's buffer (CFT, $137 \mathrm{mM} \mathrm{NaCl}, 2.7 \mathrm{mM} \mathrm{KCl}, 11.9 \mathrm{mM}$ $\mathrm{NaHCO}_{3}, 0.4 \mathrm{mM} \mathrm{NaH}_{2} \mathrm{PO}_{4}, 1.1 \mathrm{mM} \mathrm{MgCl}, 5.6 \mathrm{mM}$ D-glucose, $\mathrm{pH}$ 7.4). The thrombin inhibitor, Phe-Pro-Arg-chloromethylketone (PPACK) was from Cambridge Biosciences. Human recombinant VWF (rVWF) was from Abcam (Cambridge, UK). Oregon green-BAPTA AM and Fura Red AM were from Invitrogen (Paisley, UK). Unless indicated, all other reagents were supplied by Sigma-Aldrich.

\section{Preparation of blood samples}

Whole blood was collected into $40 \mu \mathrm{M}$ PPACK from informed consenting donors who had abstained from medication for two weeks, in accordance with the declaration of Helsinki. Blood was supplemented with $10 \mu \mathrm{M}$ PPACK hourly and stored at $37^{\circ} \mathrm{C}$ until use. For thrombus morphology experiments, platelets in whole blood were stained with $5 \mu \mathrm{M} \mathrm{DIOC}_{6}$ and treated with the follow- ing reagents or vehicle control (as indicated in the text) for $15 \mathrm{~min}$ utes (min) before use: $1 \mathrm{mM}$ aspirin, $5 \mu \mathrm{M}$ GR144053, $1 \mu \mathrm{M}$ prostaglandin $\mathrm{E}_{1}\left(\mathrm{PGE}_{1}\right.$, prostacyclin receptor agonist), $100 \mu \mathrm{M}$ 2-MeSAMP, $100 \mu \mathrm{M}$ NF449 or $100 \mu \mathrm{M}$ MRS2179. For experiments involving BAPTA treatment, whole blood was centrifuged (640g, 15 $\mathrm{min}$ ) and the platelet-rich plasma (PRP) and erythrocyte fraction were treated with DM-BAPTA-AM $\left(100 \mu \mathrm{M}, 15 \min 37^{\circ} \mathrm{C}\right)$, and reconstituted prior to experimentation.

\section{Calcium imaging}

Ratiometric $\left[\mathrm{Ca}^{2+}\right]_{\mathrm{i}}$ imaging was performed as described previously (23) with some modification. Washed platelets were prepared $(24,25)$ and incubated with $2 \mu \mathrm{M} \mathrm{PGE}_{1}, 1 \mu \mathrm{M}$ Fura Red and $1.25 \mu \mathrm{M}$ Oregon green-BAPTA $\left(30 \mathrm{~min}, 37^{\circ} \mathrm{C}\right)$ prior to centrifugation $(540 \mathrm{~g}, 15 \mathrm{~min})$. Platelet pellets were resuspended in equal volumes of $\mathrm{CFT}$ and rested at $37^{\circ} \mathrm{C}$ for $30 \mathrm{~min}$. Prior to experimentation, aliquots of whole blood were spiked with $5 \%(\mathrm{v} / \mathrm{v})$ of stained platelet suspension. For experiments examining the effect of platelet antagonists, both whole blood and stained platelets were pre-treated as described above.

\section{In vitro shear assays and image acquisition}

Glass slides (Menzel Glazer, Germany) were coated with collagen or peptide as described previously and perfused with blood in a laminar flow chamber $(1,24)$. Images showing platelet adhesion and thrombus formation were acquired using an Olympus IX81/FV300 laser scanning confocal microscope with an UplanFLN 40x, NA1.30 oil immersion objective. For morphology experiments, $\mathrm{DIOC}_{6}$-stained whole blood was perfused across a coated slide for $5 \mathrm{~min}$ at a shear rate of $1,000 \mathrm{~s}^{-1}$ and time-lapse sequences were captured at $0.2 \mathrm{~Hz}$. Residual blood was washed from the flow chamber for 1 min before $Z$ stacks encompassing the entire thrombus were acquired with a $\Delta Z$ of $0.69 \mu \mathrm{m}$ (1). Images were exported to Image (v1.45, NIH, Bethesda, MD, USA) and thresholded. The rate of change of platelet surface distribution (expressed as a percentage of the total Surface Coverage, $\Delta \mathrm{SD} / \Delta \mathrm{T}, \%$ ), was calculated from the time-lapse sequences and designated Platelet Population Mobility (PM) (24).

\section{Experimental design and statistics}

Data were collected from at least three different blood donations. For platelet/thrombus morphology measurement, means were acquired from three separate fields on each coated surface. For PM measurements, data sets were modelled using a one-phase exponential decay in GraphPad Prism 6 according to the following formula:

$$
y=\left(Y_{0}-P\right) \cdot e^{(-K x)}+P
$$

Where $\mathrm{Y}_{0}$ is the $\mathrm{Y}$ intercept, $K$ is the decay rate constant and $\mathrm{P}$ is the plateau $Y$ value. $Z$ stacks yielded measurements of Surface Coverage of platelets or thrombi, and $\mathrm{ZV}_{50}$. The plateau reflects 
the mobility of platelets interacting with a substrate. High plateau values indicate that the platelet population is in motion, whilst low values represent a stable population. $\mathrm{ZV}_{50}$ is a measure of the centre of mass of an imaged field of thrombi, thus providing a quantifiable measure of the activation state of platelets $(1,24)$.

$\left[\mathrm{Ca}^{2+}\right]_{\mathrm{i}}$ oscillations were monitored by simultaneous two-channel measurement using a 488nm argon laser. Emitted light was collected at 510-570 nm (Oregon green-BAPTA) and 610-700 nm (Fura Red). Perfusion data were acquired at $1.12 \mathrm{~Hz}$ for a period of 5 min and $\left[\mathrm{Ca}^{2+}\right]_{\mathrm{i}}$ changes were calculated as previously described (23). Individual cells were selected at random and the ratio between green and red fluorescence for each image was calculated. Fluorescence ratios were converted into molar $\mathrm{Ca}^{2+}$ concentrations using the following formula:

$$
\left[\mathrm{Ca}^{2+}\right]_{i}=K d \times\left(\frac{R-R_{\text {Min }}}{R_{\text {Max }}-R}\right) \times\left(\frac{F_{\text {Max }}}{F_{\text {Min }}}\right)
$$

where $K_{d}$ is the dissociation constant of Oregon green-BAPTA $(170 \mathrm{nM}), \mathrm{R}$ is the fluorescence ratio, $\mathrm{R}_{\min }$ is the minimum fluorescence ratio (platelets incubated with $70 \mu \mathrm{M}$ DM-BAPTA and 2 mM EGTA), $R_{\max }$ is the mean fluorescence ratio (platelets treated with $5 \mathrm{mM}$ Calcimycin $/ 2 \mathrm{mM} \mathrm{CaCl}_{2}$ ), $\mathrm{F}_{\max }$ and $\mathrm{F}_{\min }$ correspond to the respective Oregon green-BAPTA fluorescence values under $R_{\max }$ and $R_{\min }$, respectively. Up to 50 adherent platelets per coverslip were selected at random and analysed. Where combinations of surfaces and experimental conditions did not support firm platelet adhesion on at least three occasions, these were considered nonadherent conditions, and not analysed further. For example, coating with VWF-III alone supported platelet rolling but not firm adhesion. Differences among mean values were identified using analysis of variance, and Dunnett's post-hoc comparison. Data are expressed as means \pm standard error of the mean. $\mathrm{p}<0.05$ are indicated $\left({ }^{*}\right)$.

\section{Results}

\section{Platelet collagen receptors synergise to regulate stable platelet adhesion under flow conditions}

We have previously demonstrated that receptor-specific, collagenmimetic peptides can be used to assess the role of platelet collagen receptor engagement on end-point measures of thrombus formation under shear conditions $(1,8)$. More recently, we described a novel parameter, the rate of change of platelet surface distribution (designated platelet mobility, PM) that reports realtime changes in platelet adhesion, thereby quantifying dynamic platelet behaviours that are not accessible via end-point measurements (24).

To investigate real-time receptor-specific platelet activation, whole blood was perfused over type I collagen fibres, rVWF, or combinations of collagen-mimetic peptides at a shear rate of $1,000 \mathrm{~s}^{-1}$ for $5 \mathrm{~min}$. PM decreased exponentially on all adhesive surfaces, indicating that platelets exhibited high mobility prior to the onset of stable adhesion ( Figure 1A, B, Table 1). Non-adhesive surfaces $\left(\mathrm{GPP}_{10}\right)$ showed no change of PM over time. PM pro- files were ligand-specific and likely to be caused by differences in receptor-substrate recognition and subsequent signalling. On collagen and VWF-III, PM behaved as previously described (24); stable adhesion was rapid on collagen, but not on VWF-III, which supported a sustained PM, consistent with platelet rolling. No differences were observed between the PM plateau values obtained on rVWF or VWF-III-coated surfaces, indicating minimal stable adhesion on both surfaces ( Figure 1B, C). Surfaces coated with single peptides, CRP or GFOGER did not support platelet binding (1).

On GFOGER/VWF-III, plateau was $43.7 \pm 4.7 \%$, indicating that about half of the imaged platelets were in motion once initial adhesion events had reached equilibrium ( Figure 1C). Thus, a proportion of the platelets had achieved stable adhesion via $\alpha_{2} \beta_{1}$ engagement with the high affinity peptide GFOGER, in the apparent absence of a stimulus for a signalling receptor. $\mathrm{ZV}_{50}$ was low, confirming that $\alpha_{2} \beta_{1}$-engagement did not result in $\alpha_{\mathrm{II}} \beta_{3}$ activation ( Figure 1D) (1). VWF-III/CRP exhibited an intermediate rolling/adhesion state between that of collagen and GFOGER/VWFIII, with a plateau of $20.2 \pm 4.8 \%$, indicating a greater proportion of platelets had achieved stable adhesion independently of $\alpha_{2} \beta_{1}$.

In the absence of a VWF-adhesive substrate, platelets achieved static adhesion on CRP/GFOGER without prior rolling. One limitation of PM is that it takes into account non-adherent platelets within the lumen of the flow chamber. Whilst this effect is minimal on substrates with a large number of adhered platelets, it becomes pronounced when Surface Coverage is low, for example at the start of an experiment when few platelets have been able to adhere to the substrate. For example, as initial Surface Coverage is low ( Figure 1A) (1), the contribution of non-adherent platelets to PM is considerable, resulting in a high PM. As more thrombi form, the proportion of non-adherent platelets in the field of view decreases, resulting in a reduction of PM to a level more indicative of stable thrombi. Thus, on this surface, the decrease in PM does not correspond to a progressive decrease in platelet rolling and can be considered an artefact. Platelet activation was higher on CRP/ GFOGER/VWF-III than on type I collagen. This likely reflects an increased number of GpVI-binding sites in a peptide coated matrix, compared with fibrillar collagen.

These data demonstrate a clear role of multiple receptor-matrix interactions in mediating stable platelet adhesion under arteriolar shear forces. Activation leading to stable adhesion is predominantly dependent on the engagement of GpVI. $\alpha_{2} \beta_{1}$ regulates the adhesion of a subset of platelets when GpIb/V/IX is also engaged. No firm platelet adhesion was observed in the absence of both GpVI and $\alpha_{2} \beta_{1}$ engagement.

\section{Secondary signalling pathways contribute to receptor-mediated stable adhesion and thrombus formation under flow conditions.}

GpVI-mediated platelet activation and subsequent aggregation requires the induction of secondary signalling pathways including the release of thromboxane $\mathrm{A}_{2}$, ATP and ADP, reduced cAMP production and the mobilisation of $\left[\mathrm{Ca}^{2+}\right]_{\mathrm{i}}(2,11,26)$. The contribu- 


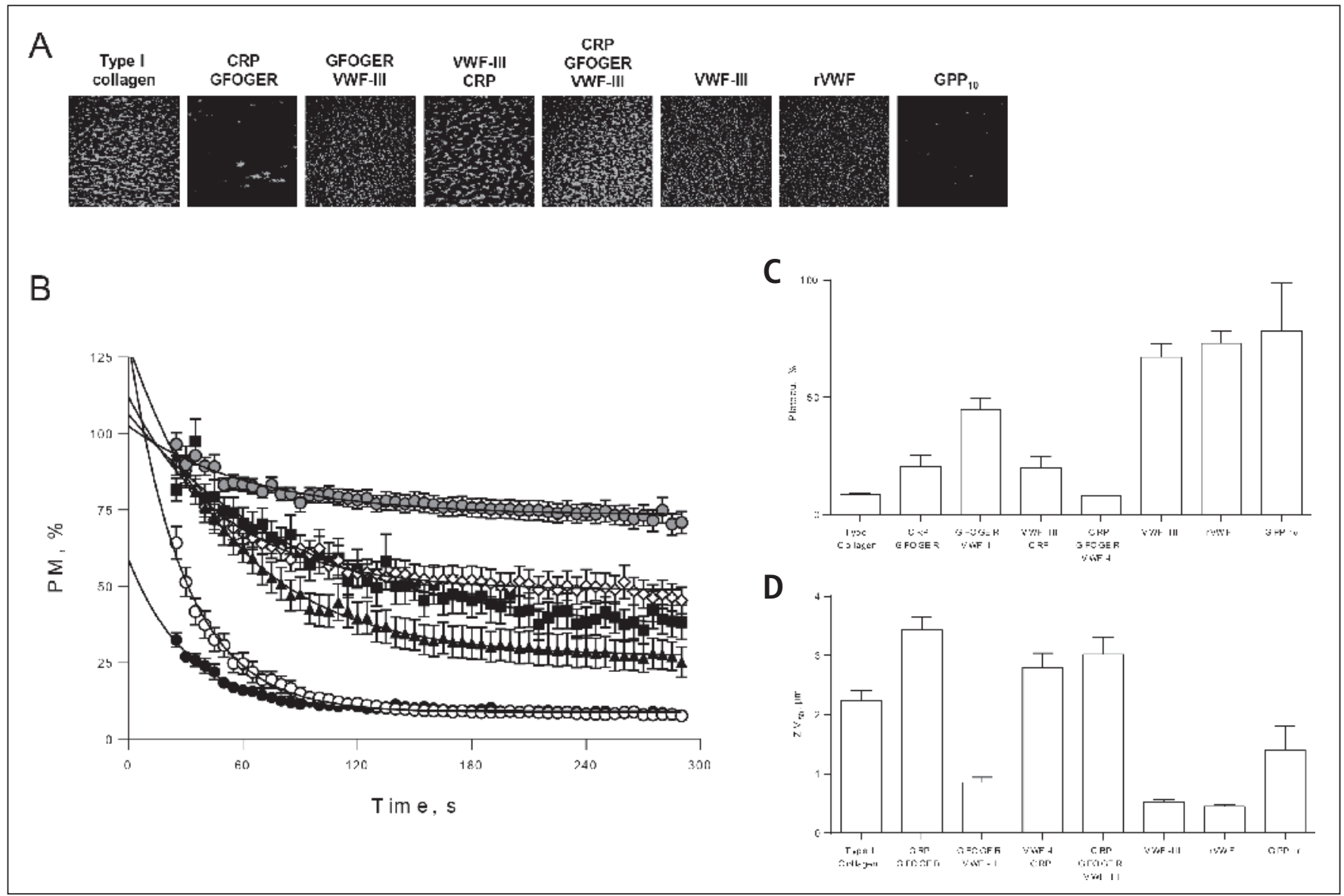

Figure 1: Dynamic platelet behaviour under flow conditions is mediated by receptor-specific peptide substrates. Whole, $\mathrm{DIOC}_{6}$-stained human blood was perfused across receptor-specific peptide substrates for 5 $\min$ at a shear rate of $1,000 \mathrm{~s}^{-1}$. Image sequences acquired at $0.2 \mathrm{~Hz}$ were processed to quantify the rate of change of platelet distribution (platelet Population Mobility, PM). High PM is evidence of a changing surface area, suggestive of platelet rolling. Low PM indicates stationary objects, such as adherent platelets or thrombi. A) Images showing platelet deposition on different thrombogenic surfaces after 5 min of blood flow at a shear rate of $1000 \mathrm{~s}^{-1}$. B) PM profiles of platelets adhering to combinations of collagen

tion of these to dynamic platelet behaviour under arteriolar flow conditions remains unclear. In order to correlate secondary signalling pathways with platelet behaviour, blood was pre-treated with antagonists or inhibitors of these secondary agonists prior to perfusion over surfaces coated with collagen and collagen-mimetic peptide combinations as before.

Experiments were performed to assess the contribution of cAMP and $\alpha_{\mathrm{II}} \beta_{3}$ activation to platelet adhesion and thrombus formation ( Figure 2, Suppl. Table 1, available online at www. thrombosis-online.com). Pre-incubation of whole blood with $\mathrm{PGE}_{1}$ did not affect Surface Coverage or PM on any surface matrix. However, $\mathrm{ZV}_{50}$ was reduced on surfaces coated with collagen (1.1 $\pm 0.1 \mu \mathrm{m}$, compared to $3.4 \pm 0.7 \mu \mathrm{M}$ vehicle treatment), CRP/ GFOGER $(1.0 \pm 0.1 \mu \mathrm{m}$ and $3.1 \pm 0.4 \mu \mathrm{m}$, respectively) and CRP/ GFOGER/VWF-III $(1.0 \pm 0.1 \mu \mathrm{m}$ and $3.8 \pm 1.1 \mu \mathrm{m}$, respectively). peptides at a shear rate of $1,000 \mathrm{~s}^{-1}$. Collagen, $\mathbf{C R P} / G F O G E R, \triangle \mathrm{GFOGER} /$ VWF-III, $\Delta$ VWF-III/CRP, ○ CRP/GFOGER/VWF-III, • VWF-III. C, D) Parameters derived from PM curves as described in Methods. C) Plateau, \%, D) ZV $\mathrm{ZV}_{50}, \mu \mathrm{m}$. Numerical data corresponding to these figures is provided in Table 1. As the Surface Coverage of platelet deposition onto $\mathrm{GPP}_{10}$ is low, the $\mathrm{ZV}_{50}$ value is influenced by non-adherent platelets in the lumen of the flow chamber. Thus, this value does not quantify thrombus formation and should be considered an artefact. Data are representative of a minimum of four independent experiments.

These data indicate an inhibitory effect of cAMP on platelet activation rather than on primary adhesion, regardless of surface coating.

Inhibition of $\alpha_{\text {IIb }} \beta_{3}$ by GR144053 abolished thrombus formation on all surfaces, as evidenced by reduction of $\mathrm{ZV}_{50}$ to approximately $0.6 \mu \mathrm{m}$, consistent with the presence of a platelet monolayer (1). On CRP/VWF-III, Surface Coverage was reduced from $27.0 \pm$ $1.6 \%$ to $8.8 \pm 1.5 \%, \mathrm{ZV}_{50}$ was reduced from $2.8 \pm 0.3 \mu \mathrm{m}$ to $0.6 \pm$ $0.1 \mu \mathrm{m}$, and plateau increased from $20.2 \pm 4.8 \%$ to $83.2 \pm 0.7 \%$, respectively ( Figure 2A-D). On CRP/GFOGER/VWF-III, GR144053 reduced Surface Coverage from $36.5 \pm 1.6$ to $16.5 \pm$ $2.6 \%$, but had no effect on plateau. Thus, whilst activation-dependent platelet-platelet interactions are mediated solely by $\alpha_{\mathrm{II}} \beta_{3}$, $\alpha_{2} \beta_{1}$ is able to contribute to stable platelet adhesion. 
We next sought to investigate the role of secondary messenger signalling in shear-dependent platelet behaviour. Whole blood was treated with aspirin (COX inhibitor), NF449 (P2X1 antagonist), MRS2179 (P2Y1 antagonist) or 2-MeSAMP (P2Y12 antagonist) prior to perfusion over receptor-specific substrates. Aspirin, MRS2179 or NF449 did not affect platelet behaviour on any surface tested, indicating that $\mathrm{TxA}_{2}$ generation, $\mathrm{P} 2 \mathrm{Y} 1$ activity or ATPgated P2X1 receptors do not contribute to platelet behaviour in this assay (Suppl. Table 1, available online at www.thrombosis-on line.com). However, despite Surface Coverage being unaffected, P2Y12 antagonism substantially reduced $\mathrm{ZV}_{50}$ on CRP/GFOGER (from $3.4 \pm 0.2 \mu \mathrm{m}$ to $1.2 \pm 0.1 \mu \mathrm{m}$ ), CRP/VWF-III (from $2.8 \pm 0.2$ to $1.3 \pm 0.2$ ) and CRP/GFOGER/VWF-III (from $3.0 \pm 0.3 \mu \mathrm{m}$ to $1.3 \pm 0.2 \mu \mathrm{m}, \nabla$ Figure 2). Interestingly, 2-MeSAMP did not affect PM on VWF-III/CRP, indicating that $\alpha_{\text {IIb }} \beta_{3}$-mediated stable adhesion is independent of P2Y12-mediated platelet activation.

Elevation of $\left[\mathrm{Ca}^{2+}\right]_{\mathrm{i}}$ is an important feature of platelet activation. We investigated the effect of intra- and extracellular $\mathrm{Ca}^{2+}$ chelation by treatment with DM-BAPTA or EDTA respectively. DM-BAPTA did not affect Surface Coverage or plateau on any surface tested. However, substantial reductions in $\mathrm{ZV}_{50}$ on collagen (from $1.9 \pm 0.2 \mu \mathrm{m}$ to $0.9 \pm 0.2 \mu \mathrm{m}$ ) CRP/GFOGER (from $4.5 \pm 0.6$ $\mu \mathrm{m}$ to $0.7 \pm 0.2 \mu \mathrm{m}$ ), VWF-III/CRP (from $4.0 \pm 0.8 \mu \mathrm{m}$ to $1.1 \pm 0.1$ $\mu \mathrm{m})$ and CRP/GFOGER/VWF-III $(4.8 \pm 0.7 \mu \mathrm{m}$ to $1.3 \pm 0.06 \mu \mathrm{m})$ were observed. These data indicate a role for GpVI-mediated $\mathrm{Ca}^{2+}$ mobilisation in thrombus development. EDTA had a profound effect on all parameters tested. For example, on VWF-III/GFOGER, EDTA reduced Surface Coverage and PM to values similar to that obtained on VWF-III alone (from $17.3 \%$ to $11.3 \pm 1.7 \%$ and from $44.8 \pm 4.8 \%$ to $76.8 \pm 4.7 \%$ respectively), reflecting the removal of extracellular divalent cations $\left(\mathrm{Ca}^{2+}\right.$ and $\left.\mathrm{Mg}^{2+}\right)$ from platelet integrins, rendering them non-functional (27).

These data indicate a requirement for functional P2Y12 receptors, $\alpha_{\mathrm{II}} \beta_{3}$ activation and $\left[\mathrm{Ca}^{2+}\right]_{\mathrm{i}}$ mobilisation for thrombus formation and stable adhesion via GpVI, $\alpha_{2} \beta_{1}$ and VWF/GpIb/ V/IX. Roles for TP ( $\mathrm{TxA}_{2}$ receptor), P2X1 or P2Y1 receptors in thrombus formation downstream of these receptors were not observed (Suppl. Table 1, available online at www.thrombosis-online. com).

\section{The contribution of platelet signalling pathways to stable adhesion in the absence of $\alpha_{\mathrm{llb}} \beta_{3}$-dependent thrombus formation}

Data presented in $>$ Figure 2 demonstrate a clear role for $\mathrm{Ca}^{2+}$ signalling and integrin activation in facilitating thrombus formation. However, whilst $\alpha_{\mathrm{II}} \beta_{3}$ inhibition abrogated thrombus formation and stable adhesion on several surfaces, the contribution of $\alpha_{2} \beta_{1}$ remains unclear. Thus, we conducted experiments on GR144053-treated platelets to investigate the contributions of secondary signalling on $\alpha_{2} \beta_{1}$ activity.

Combined treatment had little effect on thrombus morphology ( Figure 3A-C). Only combinations of GR144053/PGE 1 and GR144053/EDTA reduced Surface Coverage on collagen relative to GR144053 treatment alone ( Figure 3B). A greater effect of
$\alpha_{\mathrm{II}} \beta_{3}$ antagonism was observed on dynamic parameters of platelet behaviour ( Figure 3A-D). GR144053/DM-BAPTA, GR144053/PGE 1 or GR144053/MRS2179 all increased plateau on CRP/GFOGER relative to GR144053 treatment alone. Plateau was also increased by GR144053/DM-BAPTA on CRP/GFOGER/ VWF-III, and by GR144053/2-MeSAMP on GFOGER/VWF-III. Interestingly, GR144053/DM-BAPTA did not increase the plateau on collagen, suggesting that $\mathrm{Ca}^{2+}$-independent procresses may be involved in stable adhesion on this substrate. These data indicate a role for P2Y12 receptors and $\mathrm{Ca}^{2+}$ signalling in the promotion of stable platelet adhesion to surfaces containing an $\alpha_{2} \beta_{1}$-adhesive ligand.

\section{Platelet $\left[\mathrm{Ca}^{2+}\right]_{\mathrm{i}}$ fluctuations occur in a substrate- specific manner}

Elevation of platelet $\left[\mathrm{Ca}^{2+}\right]_{\mathrm{i}}$ follows engagement of collagen receptors under flow conditions $(6,16,18,20)$. As inhibition of $\left[\mathrm{Ca}^{2+}\right]_{\mathrm{i}}$ signalling by loading with DM-BAPTA resulted in the abrogation of platelet activation (exemplified by a reduction in $\mathrm{ZV}_{50}$ on surfaces coated with GpVI-binding ligands), further experiments were performed to measure single cell $\left[\mathrm{Ca}^{2+}\right]_{\mathrm{i}}$ fluctuations upon receptor-specific adhesion at arteriolar shear $\left(1,000 \mathrm{~s}^{-1}\right)$, following secondary signal antagonism.

Initially, average $\left[\mathrm{Ca}^{2+}\right]_{i}$ values were assessed (mean of $>500$ platelets, Figure $4 \mathrm{~A}$ ). $\left[\mathrm{Ca}^{2+}\right]_{\mathrm{i}}$ levels increased upon platelet adhesion and peaked at around $90 \mathrm{~s}$ on all substrates tested. The maximum $\left[\mathrm{Ca}^{2+}\right]_{i}$ attained was highest on collagen fibres and CRP/GFOGER/VWF-III and peaked at around $600 \mathrm{nM}$, followed by CRP/VWF-III and CRP/GFOGER (both approximately 500 $\mathrm{nM}$ ), whilst GFOGER/VWF-III induced the lowest response (approximately $250 \mathrm{nM}$ ). Interestingly, increased $\left[\mathrm{Ca}^{2+}\right]_{i}$ values correlated with decreased plateau values ( $\triangleright$ Figure 1C). These data are consistent with a predominant role for GpVI in collagen-evoked platelet $\left[\mathrm{Ca}^{2+}\right]_{\mathrm{i}}$ signalling leading to thrombus formation under arterial shear, which are augmented by either $\alpha_{2} \beta_{1}$ or GpIb/V/IX. In combination with $\alpha_{2} \beta_{1}$, GpIb/V/IX induces a substantially smaller $\left[\mathrm{Ca}^{2+}\right]_{\mathrm{i}}$ increase, which results in stable platelet adhesion, but not full activation leading to thrombus formation ( $\$$ Figure 1 , $>$ Table 1).

Following firm adhesion, single platelet $\left[\mathrm{Ca}^{2+}\right]_{\mathrm{i}}$ responses were heterogeneous. Four subtypes of $\left[\mathrm{Ca}^{2+}\right]_{\mathrm{i}}$ response were identified in platelets adhering to different substrates: transient spikes, prolonged bursts, flat lines and traces where a prolonged burst was preceded by a transient spike (denoted spike-bursts traces, $\boldsymbol{\nabla}$ Figure 4B) (20). Example traces are shown in $>$ Figure 4C, and terminology is defined as follows. Transient spikes (e.g. in traces from platelets adhering to GFOGER/VWF-III) last no longer than $30 \mathrm{~s}$ before returning to background level. Prolonged bursts lasted for longer than $30 \mathrm{~s}$. Spike-bursts have a clear transient spike preceding a burst lasting for more than $30 \mathrm{~s}$. Flat lines have no increase on background $\left[\mathrm{Ca}^{2+}\right]_{\mathrm{i}}$.

The frequency of the different trace profiles were similar in platelets adhering to collagen fibres and CRP/GFOGER/VWF-III, indicating that collagen receptors other than GpVI, $\alpha_{2} \beta_{1}$ and 
Figure 2:

Antagonism or inhibition of platelet activatory pathways alters platelet behaviour and morphology of thrombi formed on receptor-specific peptide substrates under shear conditions. DIOC $_{6}$-stained whole human blood was pretreated with the stated antagonists before being perfused over collagen or combinations of collagen-mimetic peptides at a shear rate of $1,000 \mathrm{~s}^{-1}$ for $5 \mathrm{~min}$. A) Representative images showing thrombus deposition on different thrombogenic surfaces following antagonist or inhibitor treatment. B-F) Quantification of endpoint and dynamic parameters of thrombus formation. B) Surface Coverage, \%, C) ZV 50 , $\mu \mathrm{m}$ D) Plateau, \%.Data are representative of a minimum of four independent experiments. * indicates $p<0.05$. Numerical data corresponding to these figures is provided in Suppl. Table 1 (available online at www.thrombosis-online. com).

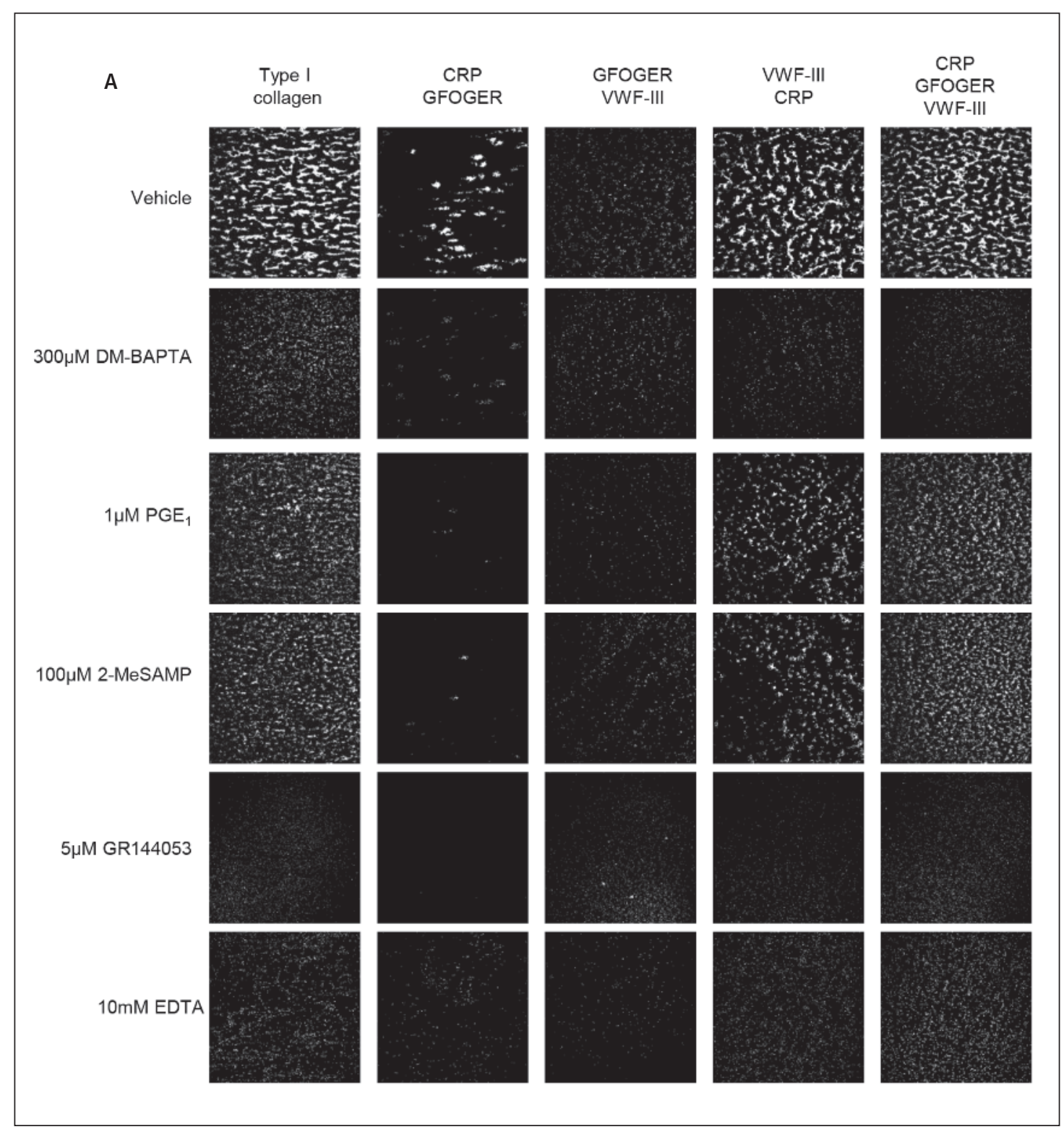

GpIb/V/IX do not contribute to $\left[\mathrm{Ca}^{2+}\right]_{\mathrm{i}}$ signalling ( $>$ Figure $4 \mathrm{D}$ ). These surfaces had the highest proportion of spike-bursts and the fewest flat lines, suggesting that spike-bursts represent a full $\left[\mathrm{Ca}^{2+}\right]_{i}$ signal, arising from the synergism between all three collagen receptor axes. Equal proportions of platelets elicited transient spikes or prolonged bursts. Omission of CRP or VWF-III reduced the proportion of spike-bursts. Significantly more $\mathrm{Ca}^{2+}$ spikes were recorded in platelets adhering to GFOGER/VWF-III than for any other substrate tested. Flat lines were also more frequent on this surface, and the number of prolonged bursts and spike-bursts were reduced. The proportions of trace types were similar on CRP/ GFOGER and VWF-III/CRP surfaces, indicating that either $\alpha_{2} \beta_{1}$ or GpIb/V/IX can potentiate GpVI-dependent $\left[\mathrm{Ca}^{2+}\right]_{\mathrm{i}}$ signals.

\section{Discussion}

Platelet adhesion and activation during thrombogenesis is a dynamic process, involving transient and sustained interactions between platelets and sub-endothelial proteins in a variable haemodynamic environment. Previously, we used synthetic collagenmimetic peptides to study receptor-dependent platelet thrombus formation under different shear conditions $(1,8)$. Whilst this work quantified end-point parameters of thrombus formation, providing an overview of the roles of platelet collagen receptors in thrombogenesis, it omitted any assessment of dynamic platelet behaviour and did not investigate the contribution of secondary signalling to receptor-specific platelet behaviour. Here, we describe the combined use of collagen-mimetic peptides and antagonists of secondary signalling pathways to investigate the effects of platelet col- 


\section{B}

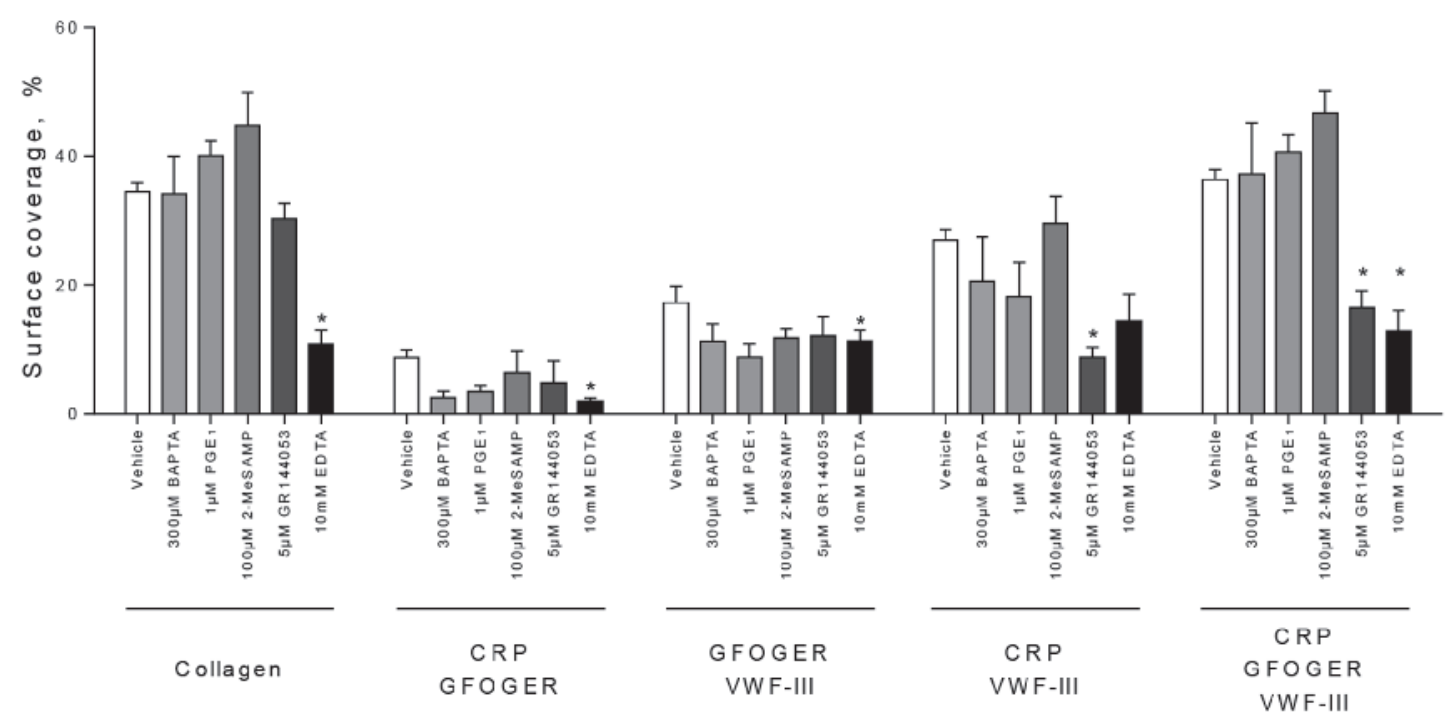

C

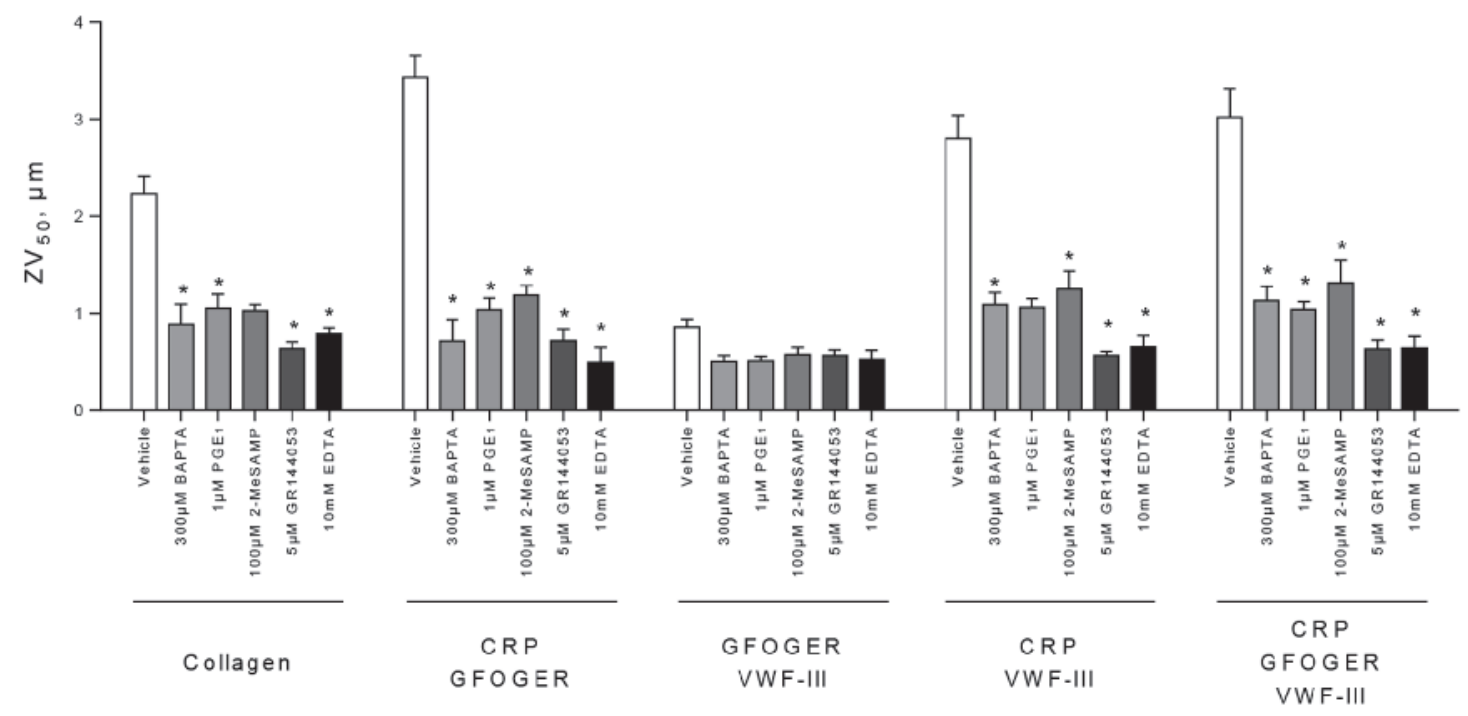

D

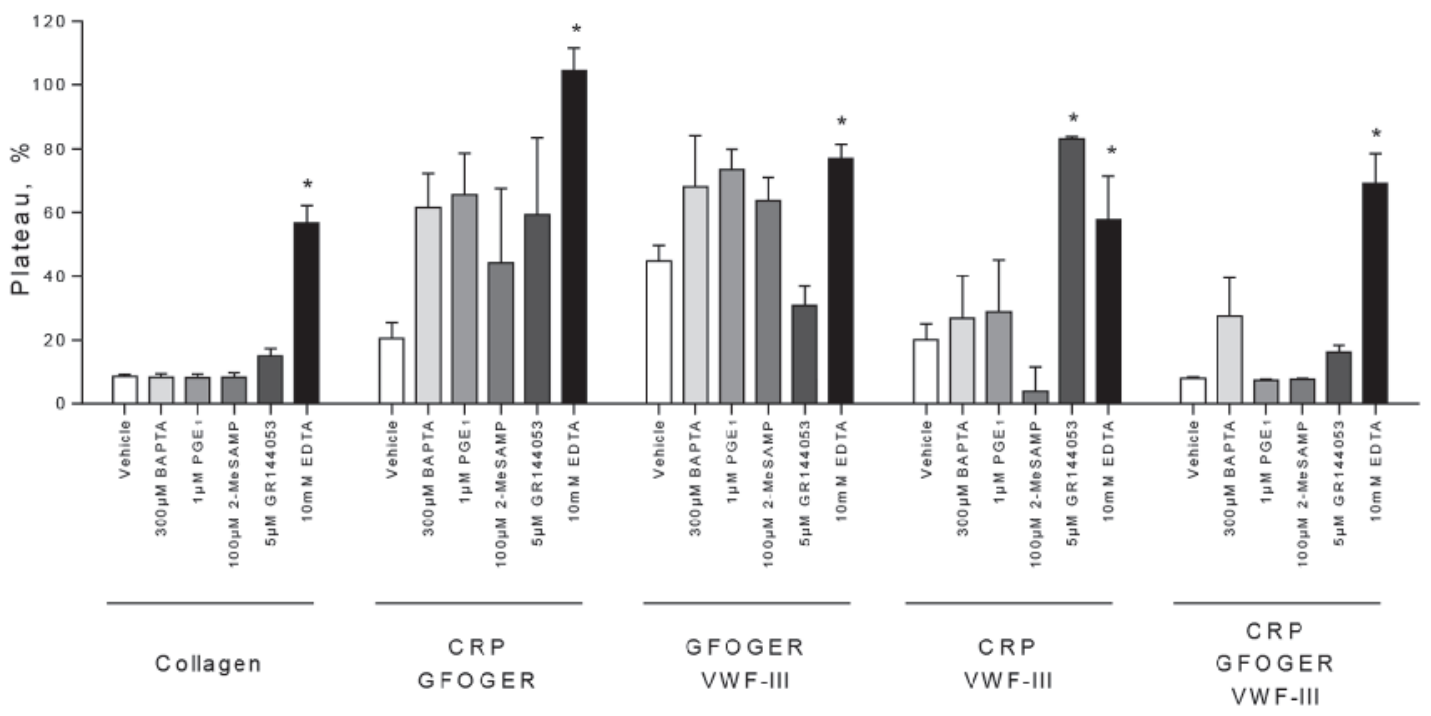


Figure 3:

Combined drug treatment with $\alpha_{\mathrm{Ilb}} \beta_{3}$ antagonism reveals the effects of specific signalling pathways on $\alpha_{2} \beta_{1}$ activation under shear conditions.

DIOC $_{6}$-stained whole human blood was pre-treated with $5 \mu \mathrm{M}$ GR144053 in combination with other antagonists of platelet activatory pathways (previously described in Figure 2). A) Representative images showing thrombus deposition on different thrombogenic surfaces. B-D) End-point and dynamic parameters of platelet behaviour were quantified as before. B) Platelet or thrombus Surface Coverage (\%). C) $\mathrm{ZV}_{50}(\mu \mathrm{m})$, D) Plateau, \%. Data are representative of a minimum of four independent experiments. * indicates $p<0.05$. Numerical data corresponding to these figures is provided in Suppl. Table 2 (available online at www.thrombosis-online. com).

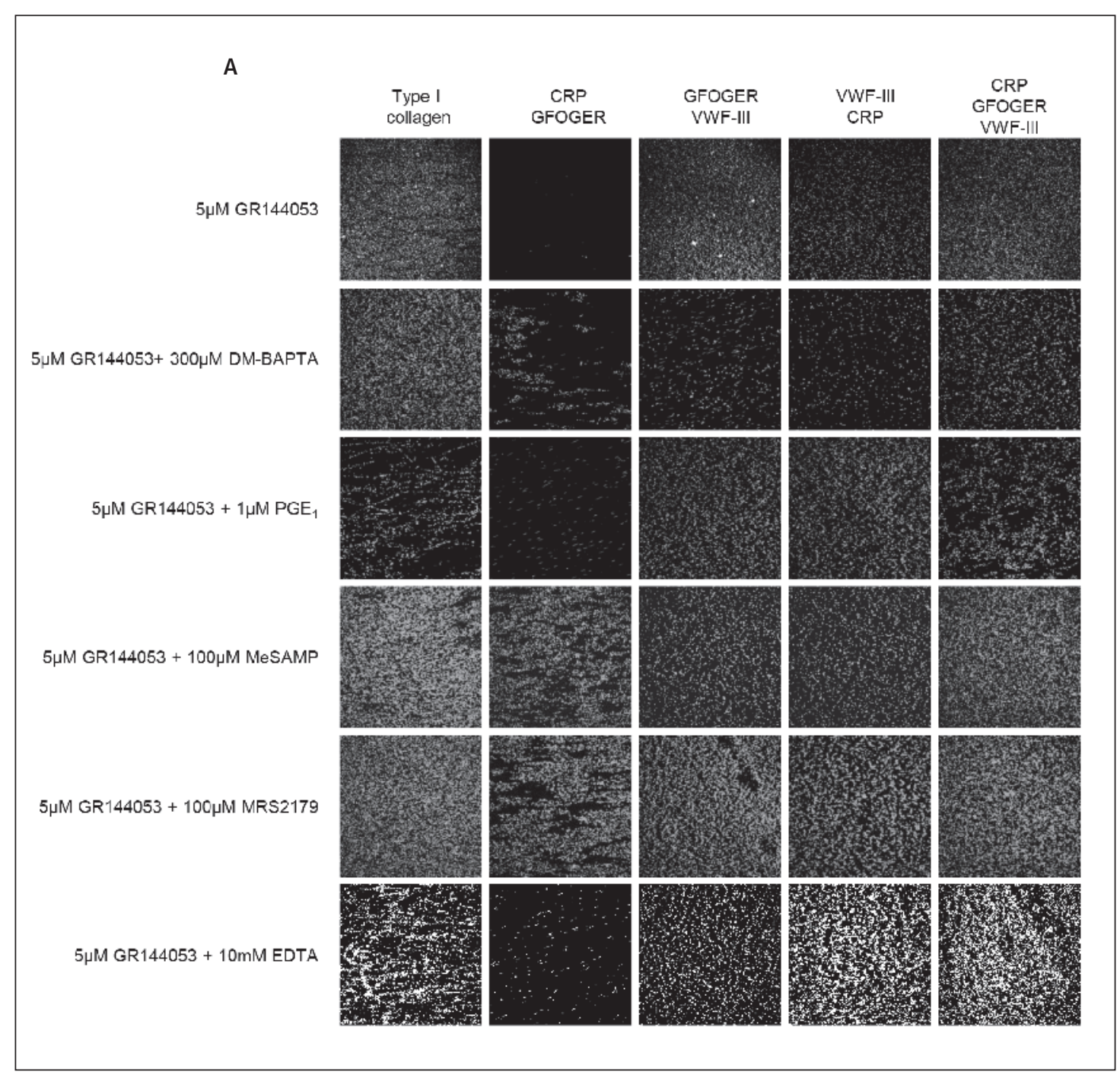

lagen receptor engagement on changes of platelet $\left[\mathrm{Ca}^{2+}\right]_{\mathrm{i}}$ levels during the transition between transient and stable platelet adhesion prior to thrombus formation. Platelet behaviour was quantified using a number of previously-assessed parameters (Surface Coverage, $Z_{50}$, etc) in addition to the novel parameter PM, which quantifies the degree to which the platelet population achieves stable adhesion in real-time under flow conditions (24). By correlating these measurements with corresponding patterns of $\left[\mathrm{Ca}^{2+}\right]_{\mathrm{i}}$ increase and the effects of specific antagonists, we provide a definitive assessment of the effects of activatory signalling pathways on platelet behaviour following adhesion to collagen under arterial flow conditions.

Previous work has characterised $\left[\mathrm{Ca}^{2+}\right]_{\mathrm{i}}$ signals in platelets adhering to coated collagen, VWF or fibrinogen under flow conditions $(6,12-21,23,28-30)$. Inhibition of receptors with antibodies indicated a requirement for $\mathrm{GPVI}$ activity to generate full calcium responses in platelets adhering to collagen fibres at a shear rate of $1,000 \mathrm{~s}^{-1}$ (6). Inhibition of $\alpha_{2} \beta_{1}$ partially reduced the calcium increase. Mazzucato et al. (20), identified two types of $\mathrm{Ca}^{2+}$ signal at low shear $\left(250 \mathrm{~s}^{-1}\right)$; transient peaks ( $\alpha$ peaks) which were attributed to $\alpha_{2} \beta_{1}$ engagement, and sustained signals ( $\gamma$ peaks) which are initiated by GpVI. However, the contribution of GpIb/V/IX to $\left[\mathrm{Ca}^{2+}\right]_{i}$ signalling in response to collagen was not assessed in their study. At the shear rate used, it is possible that the accrual of VWF onto collagen is minimal $(12,29)$, By using the collagenous peptide, VWF-III, as a ligand for plasma VWF, we have been able to assess the influence of GpIb/V/IX directly on $\left[\mathrm{Ca}^{2+}\right]_{i}$ signalling under shear conditions alongside the roles of GpVI and $\alpha_{2} \beta_{1}$.

Our data are consistent with a model of collagen-induced, shear-dependent activation in which GpIb/V/IX mediates transient platelet interaction via VWF, whilst an integrin (either $\alpha_{\mathrm{II}} \beta_{3}$ or $\alpha_{2} \beta_{1}$ ) mediates stable adhesion. GpIb/V/IX and $\alpha_{2} \beta_{1}$ synergise to generate $\left[\mathrm{Ca}^{2+}\right]_{\mathrm{i}}$ spikes, which induce integrin-dependent stable adhesion, but not thrombus formation. GpVI is the predominant activatory receptor, engagement of which induces sustained $\left[\mathrm{Ca}^{2+}\right]_{\mathrm{i}}$ increases, leading to $\alpha_{\mathrm{II}} \beta_{3}$-dependent stable adhesion and thrombus formation. Platelet activation $\left(\mathrm{ZV}_{50}\right)$ is inhibited by $\mathrm{PGE}_{1}$, confirming an inhibitory role for cAMP. Interestingly, the effect of 


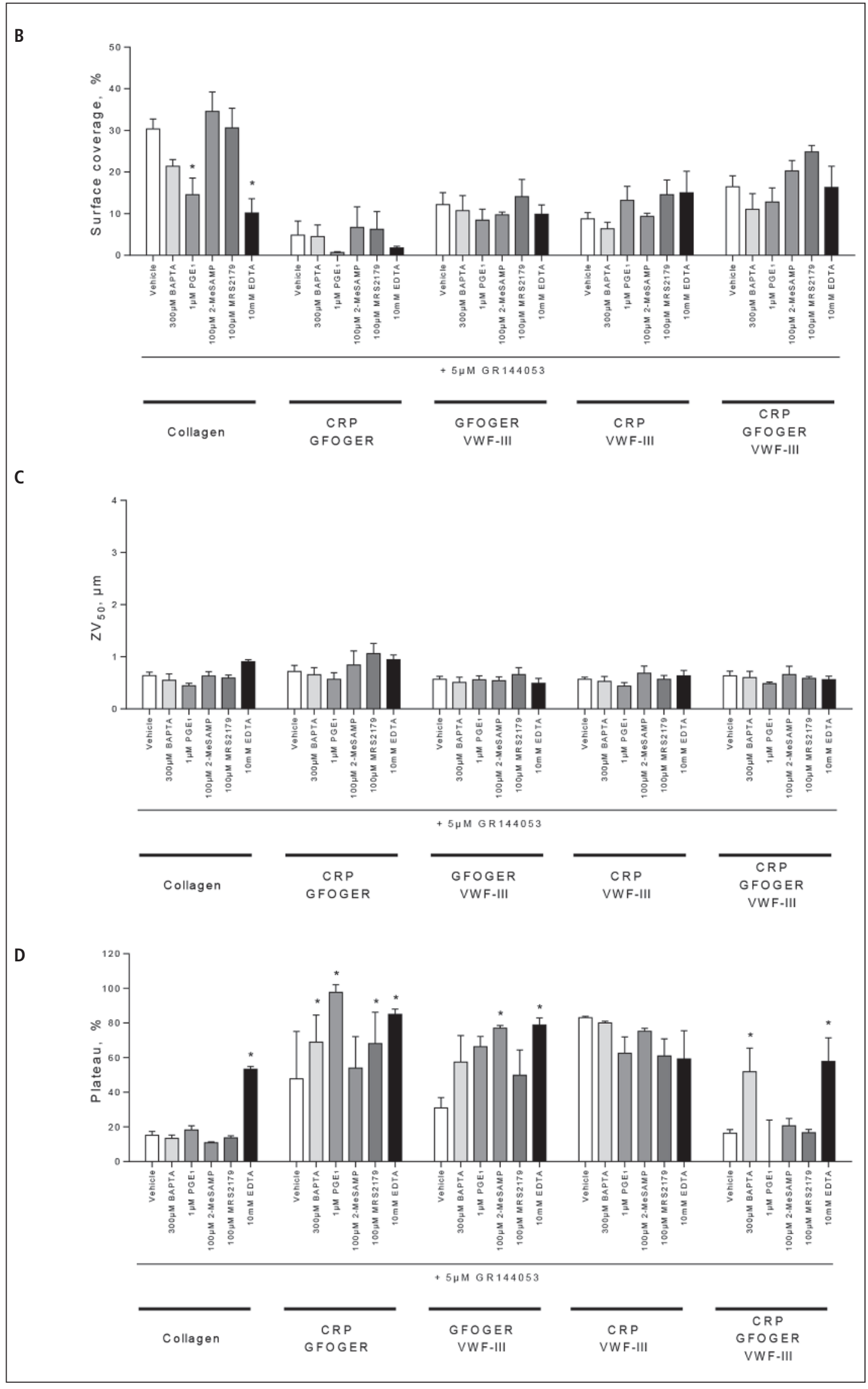

Figure 3: Continued 


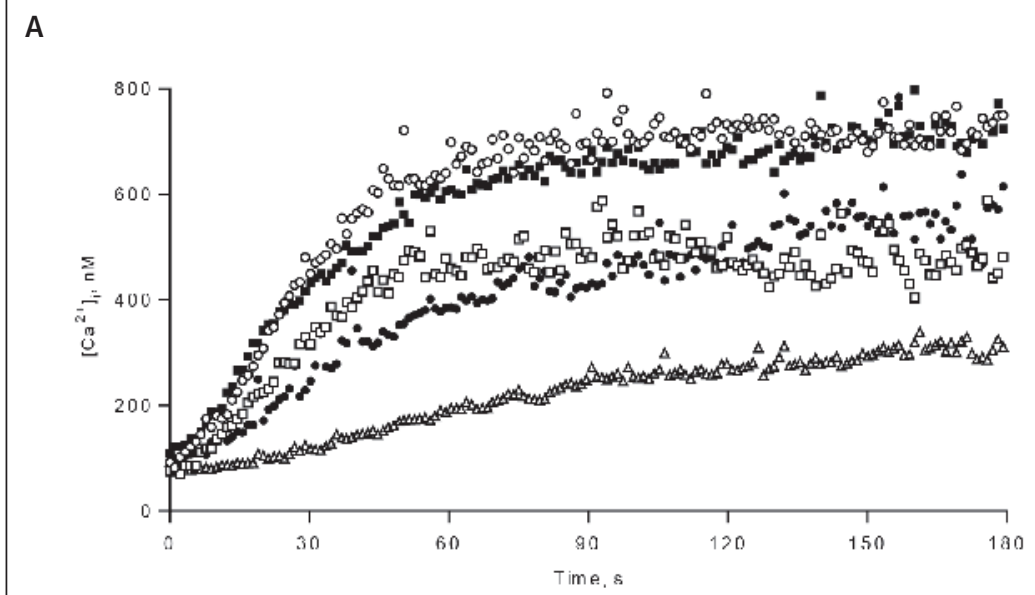

B
i) Transient spikes
ii) Prolonged burst
iii) Spike-burst
iv) Flat line
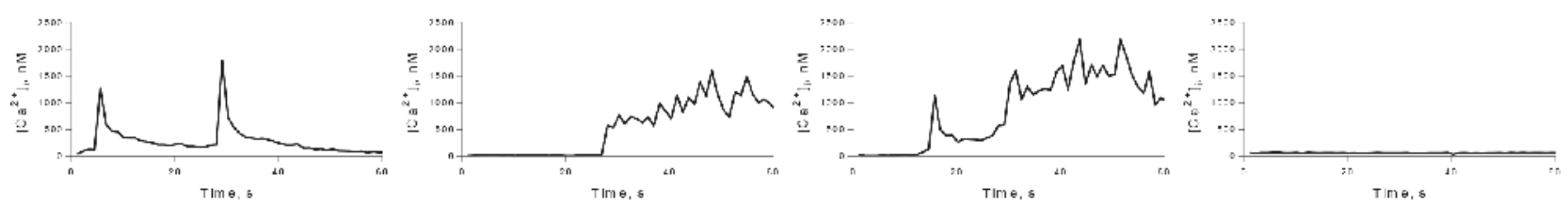

C

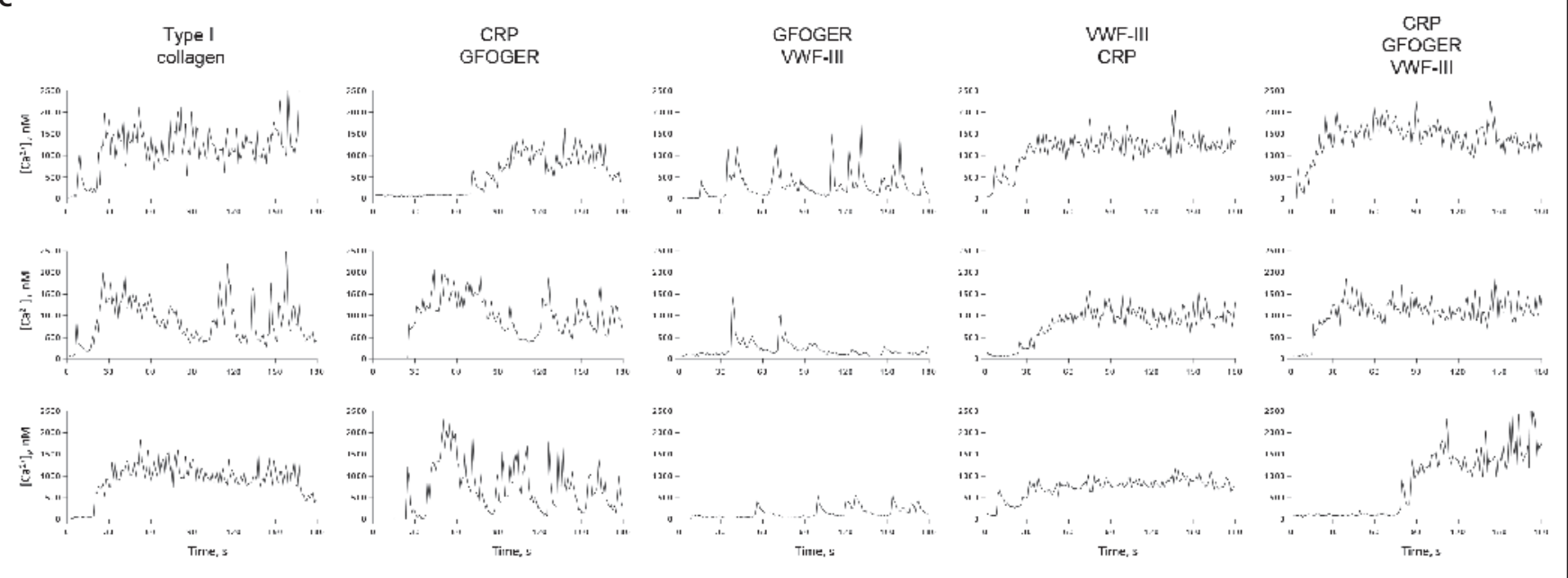

Figure 4: Heterogeneous $\left[\mathrm{Ca}^{2+}\right]_{i}$ signalling is observed in platelets adhering to receptor-specific peptide substrates under flow conditions. A) $\left[\mathrm{Ca}^{2+}\right]_{\mathrm{i}}$ levels were recorded in single platelets adhering to collagen or combinations of collagen-mimetic peptides at a shear rate of $1,000 \mathrm{~s}^{-1}$. Average $\left[\mathrm{Ca}^{2+}\right]_{i}$ were calculated from 50 cells imaged in a given experiment. Traces were normalised so that firm platelet adhesion occurred at time 0 Data are representative of a minimum of 20 independent experiments. $\bigcirc \mathrm{Col}-$ lagen, $\square$ CRP/GFOGER, $\triangle$ GFOGER/VWF-III, • VWF-III/CRP, — CRP/GFOGER/ VWF-III. B) Different patterns of $\left[\mathrm{Ca}^{2+}\right]_{i}$ oscillations are observed in single platelets adhering to receptor-specific peptide substrates under flow conditions. Examples of the different trace types observed in these experiments in- cluded: i) transient spikes, ii) prolonged burst, iii) spike-bursts and iv) flat lines. For clarity, only the first 60 s of each trace is shown. C) Traces showing representative patterns of $\left[\mathrm{Ca}^{2+}\right]_{i}$ oscillations recorded from single platelets. Examples of transient $\left[\mathrm{Ca}^{2+}\right]_{i}$ spikes can be seen on GFOGER/VWF-III. "Spikebursts" are best represented on Type I collagen (upper two traces) and CRP/ GFOGER/VWF-III (upper and lower traces). Prolonged bursts can be seen on Type I collagen (lower trace), CRP/GFOGER (middle trace) and CRP/GFOGER/ VWF-III (middle trace). D) Different patterns of $\left[\mathrm{Ca}^{2+}\right]_{i}$ signal were obtained from platelets adhering to collagen or collagen peptides at a shear rate of $1,000 \mathrm{~s}^{-1}$. Transient spike, $\square$ prolonged burst, $\square$ spike-burst, $\square$ flat line. 


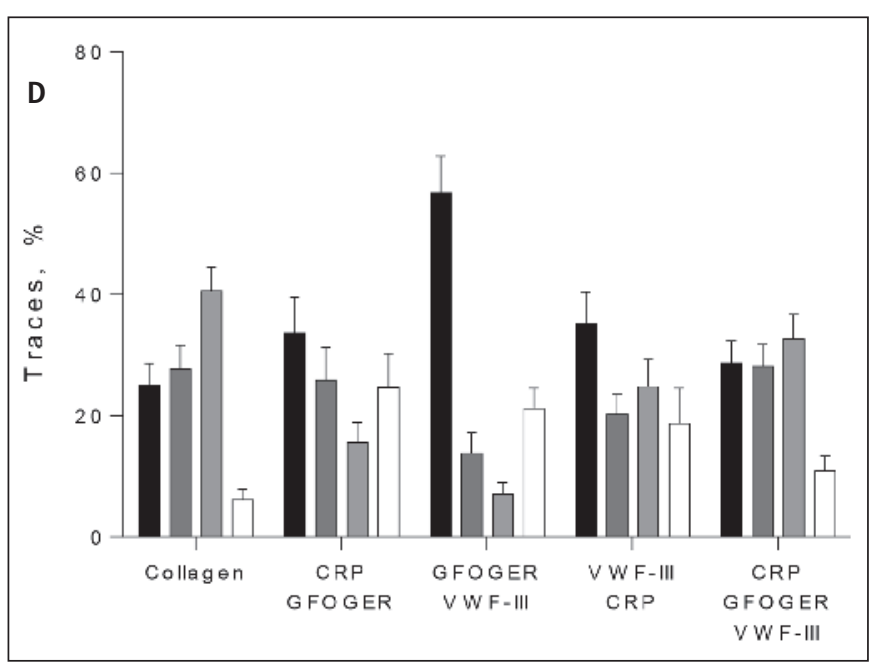

Figure 4: Continued

DM-BAPTA and PGE $_{1}$ were similar, supporting a role for cAMPmediated inhibition of $\mathrm{IP}_{3}$ receptor-dependent calcium release (31, 32). P2Y12 signalling acts downstream of GpVI engagement. It does not influence stable adhesion, but mediates $\alpha_{\mathrm{II}} \beta_{3}$-dependent platelet-platelet interactions leading to thrombus formation.

In CRP/GFOGER/VWF-III, we have generated a collagen-mimetic surface that engages all known platelet receptors that regulate collagen-dependent thrombus formation. Platelet behaviour following interaction with CRP/GFOGER/VWF-III closely resembles that of the interaction with collagen. On both surfaces, PM undergoes a high to low transition indicating initial mobility followed stable adhesion (24). A similar proportion of spike-burst traces were observed on collagen and CRP/GFOGER/VWF-III, showing that engagement of platelet collagen receptors other than GpVI, $a_{2} \beta_{1}$ and GpIb/V/IX is not required for a full $\left[\mathrm{Ca}^{2+}\right]_{i}$ signal.

The identification of $\alpha_{2} \beta_{1}$ and $\alpha_{\mathrm{II}} \beta_{3}$ as the principle adhesive receptors can be inferred by omission of GFOGER from a replete peptide-coated surface with coincident antagonism of $\alpha_{\mathrm{IIb}} \beta_{3}$. This restores PM to a value comparable to that of VWF-III alone. Therefore, at least one integrin is a pre-requisite for stable adhesion under flow conditions. Other platelet integrins, such as $\alpha_{v} \beta_{3}, \alpha_{5} \beta_{1}$ or $\alpha_{6} \beta_{1}$ could presumable substitute as adhesive receptors in vivo if their cognate ligands (e.g. fibronectin, vitronectin) were accessible.

Consistent with previous work, aspirin, NF449 or MRS2179 did not affect platelet behaviour or thrombus formation (20, 33-35). Thus, TP-, P2X1- and P2Y1-induced signals are absent or weak at arteriolar shear, possibly being overwhelmed by stronger signals initiated by GpVI and P2Y12. These signalling pathways may become more significant at lower shear rates, or if the primary stimulus is weak (34). The observation that $\mathrm{PGE}_{1}$, cytosolic DMBAPTA and 2-MeSAMP inhibit thrombus formation but not stable adhesion highlights a mechanistic difference between stable adhesion and platelet-platelet interactions leading to thrombus formation. Whilst both processes are regulated by $\alpha_{\mathrm{II}} \beta_{3}$, different secondary signals affect adhesion and thrombus formation differ-
Table 1: Dynamic platelet behaviour under flow conditions is mediated by receptor-specific peptide substrates. To investigate receptorspecific platelet behaviour in real-time, we perfused DiOC $_{6}$-stained platelets in whole blood over type I collagen, VWF or combinations of collagen-mimetic peptides at a shear rate of $1,000 \mathrm{~s}^{-1}$ for 5 min during which PM measurements were calculated. Numerical values corresponding to the different parameters and surfaces are provided. Of note, as platelet deposition onto $\mathrm{GPP}_{10}$ (and thus Surface coverage) is low, the $\mathrm{ZV}_{50}$ value is influenced by non-adherent platelets in the lumen of the flow chamber. Thus, this value does not quantify thrombus formation and should be considered an artefact.

\begin{tabular}{l|l|l|l}
\hline Substrate & $\begin{array}{l}\text { Surface } \\
\text { coverage }(\%)\end{array}$ & $Z_{50}(\mu \mathrm{m})$ & Plateau (\%) \\
\hline Collagen & $34.5 \pm 1.4$ & $2.2 \pm 0.2$ & $8.6 \pm 0.6$ \\
\hline CRP/GFOGER & $8.7 \pm 1.2$ & $3.4 \pm 0.2$ & $20.5 \pm 4.9$ \\
\hline GFOGER/VWF-III & $17.3 \pm 2.6$ & $0.9 \pm 0.1$ & $44.8 \pm 4.8$ \\
\hline VWF-III/CRP & $27.0 \pm 1.6$ & $2.8 \pm 0.2$ & $20.2 \pm 4.8$ \\
\hline CRP/GFOGER/VWF-III & $36.4 \pm 1.6$ & $3.0 \pm 0.3$ & $8.0 \pm 0.4$ \\
\hline VWF-III & $10.0 \pm 1.2$ & $0.5 \pm 0.0$ & $67.2 \pm 5.8$ \\
\hline rVWF & $13.5 \pm 1.3$ & $0.5 \pm 0.0$ & $73.1 \pm 5.1$ \\
\hline GPP 10 & $0.4 \pm 0.1$ & $1.4 \pm 0.4$ & $78.1 \pm 20.6$ \\
\hline
\end{tabular}

entially. For example, these antagonists all reduce thrombus formation (measured by $\mathrm{ZV}_{50}$ ) on VWF-III/CRP without affecting PM and thus, stable adhesion. The mechanisms responsible for this dual response are unclear, but may be attributable to differential $\alpha_{\mathrm{II}} \beta_{3}$ activity. In the scheme we envisage, initial binding is responsible for platelet adhesion whilst subsequent outside-in signalling leads to increased receptor activity resulting in platelet-platelet interactions (36). Alternatively, this effect may be attributable to synergism between GpIb/V/IX and non-activated $\alpha_{\mathrm{II}} \beta_{3}$ with surface-bound VWF. Support for this hypothesis comes from recent work showing that shear-dependent clustering of GpIb/V/IX leads to up-regulation of $\alpha_{\text {II }} \beta_{3}$ activity $(37,38)$. This increased adhesive effect is not present in platelets that are participating in platelet-platelet interactions and are not in contact with VWF. Further work is required to resolve this issue.

PM highlights the role of GpVI in stable adhesion. Omission of $\mathrm{CRP}$ (and thus GpVI activity) from a replete peptide coated surface produces a pronounced increase in mobility, reflecting the critical role of platelet activation in integrin behaviour. However, as PM is lower on GFOGER/VWF-III than on VWF-III alone, a proportion of platelets (approximately $50 \%$ ) achieved stable adhesion via $\alpha_{2} \beta_{1}$ without an activatory stimulus from GpVI. This is consistent with previous work showing that platelets adhere to GFOGER under static conditions with a high affinity that is not increased by activation with ADP (6). Whilst adhesion to GFOGER/VWF-III is increased, $\mathrm{ZV}_{50}$ does not differ from that of VWF-III alone and is unaffected by GR144053, indicating that platelets are not activated on this surface. The sub-maximal adhesion on GFOGER/VWF-III is associated with transient $\left[\mathrm{Ca}^{2+}\right]_{\mathrm{i}}$ signals which are not large enough to elicit $\alpha_{\mathrm{II}} \beta_{3}$-dependent thrombus formation. However, signals from these receptors po- 


\section{What is known about this topic?}

- Platelet receptors GpVI, $\alpha_{2} \beta_{1}, \alpha_{11 b} \beta_{3}$ and Gplb/V/IX/VWF regulate platelet adhesion and activation in response to collagen.

- Receptor engagement differentially influences intracellular platelet calcium signals.

\section{What does this paper add?}

- This study utilises novel, dynamic image analysis of platelet adhesion to receptor-specific ligands to correlate primary and secondary signalling with platelet behaviour, intracellular calcium fluctuations and thrombus formation under arteriolar shear conditions.

- Differential receptor engagement results in heterogeneous intracellular calcium signals that correlate with varying levels of platelet adhesion and activation. Engagement of GpVI results in the largest calcium signals.

- Integrin $\alpha_{\| 1 b} \beta_{3}$ has biochemically distinct roles in platelet adhesion to a substrate, and in platelet-platelet interactions leading to thrombus formation.

tentiate GpVI-dependent signalling, which, once engaged, generates large sustained $\mathrm{Ca}^{2+}$ signals, sufficient for $\alpha_{\mathrm{II}} \beta_{3}$ and $\alpha_{2} \beta_{1}$ activation, stable adhesion and generation of large thrombi.

Combined antagonism of $\alpha_{\mathrm{IIb}} \beta_{3}$ with other secondary signalling pathways isolates the effects of specific signalling pathways on $\alpha_{2} \beta_{1}$ activation. Our data confirm that $\alpha_{2} \beta_{1}$ activation is dependent on extracellular divalent cations and is inversely correlated with cAMP levels. Our data also suggests that $\alpha_{2} \beta_{1}$ activation occurs downstream of P2Y12 signalling $(39,40)$. However, contrary to previous reports measuring platelet adhesion to collagen under static conditions (39), we show that $\alpha_{2} \beta_{1}$ activation under flow conditions is $\left[\mathrm{Ca}^{2+}\right]_{\mathrm{i}}$-dependent. The reason for this difference is unclear, although static conditions may favour $\alpha_{2} \beta_{1}$-dependent adhesion without activation, as previously described (6). It may be that, on collagen surfaces at least, other weaker integrin motifs not tested here directly may contribute to platelet adhesion after $\alpha_{2} \beta_{1}$ activation. Shear forces may provide sufficient energy to prevent non-activated $\alpha_{2} \beta_{1}$ from engagement with its cognate ligand.

In conclusion, our data support the conclusion that GpVI is the major signalling collagen receptor on platelets under flow conditions. Whilst GpVI engagement results in a sustained $\left[\mathrm{Ca}^{2+}\right]_{\mathrm{i}} \mathrm{elev-}$ ation that is sufficient for $\alpha_{2} \beta_{1}$ - and $\alpha_{\text {IIb }} \beta_{3}$-dependent stable adhesion, P2Y12 signals are required for $\alpha_{\mathrm{II}} \beta_{3}$-dependent plateletplatelet interactions leading to full thrombus formation. $\alpha_{2} \beta_{1}$ and $\mathrm{GpIb} / \mathrm{V} / \mathrm{IX}$ are able to generate transient $\mathrm{Ca}^{2+}$ signals which are not sufficient to activate $\alpha_{\mathrm{II}} \beta_{3}$, but act to potentiate or augment GpVI signalling. $\alpha_{\mathrm{II}} \beta_{3}$ has distinct, separable roles in mediating stable adhesion and promoting thrombus formation.

\section{Author contributions}

N.P. designed experiments, performed research, analysed data, and wrote the manuscript. B.M. performed research. D.B. syn- thesised peptides. K.T. and M.M-S wrote the manuscript. R.W.F. designed experiments, analysed data, and wrote the manuscript.

\section{Conflicts of interest}

None declared.

\section{References}

1. Pugh N, Simpson AMC, Smethurst PA, et al. Synergism between platelet collagen receptors defined using receptor-specific collagen-mimetic peptide substrata in flowing blood. Blood 2010; 115: 5069-5079.

2. Nieswandt B, Watson SP. Platelet-collagen interaction: is GPVI the central receptor? Blood 2003; 102: 449-461.

3. Ruggeri ZM, Mendolicchio GL. Adhesion mechanisms in platelet function. Circ Res 2007; 100: 1673-1685.

4. Kehrel B, Wierwille S, Clemetson KJ, et al. Glycoprotein VI is a major collagen receptor for platelet activation: it recognizes the platelet-activating quaternary structure of collagen, whereas CD36, glycoprotein IIb/IIIa, and von Willebrand factor do not. Blood 1998; 91: 491-499.

5. Verkleij MW, Morton LF, Knight CG, et al. Simple Collagen-Like Peptides Support Platelet Adhesion Under Static But Not Under Flow Conditions: Interaction Via $\mathrm{a} 2 ß 1$ and von Willebrand Factor With Specific Sequences in Native Collagen Is a Requirement to Resist Shear Forces. Blood 1998; 91: 3808-3816.

6. Siljander PR-M, Munnix ICA, Smethurst PA, et al. Platelet receptor interplay regulates collagen-induced thrombus formation in flowing human blood. Blood 2004; 103: 1333-1341.

7. Lisman T, Raynal N, Groeneveld D, et al. A single high-affinity binding site for von Willebrand factor in collagen III, identified using synthetic triple-helical peptides. Blood 2006; 108: 3753-3756.

8. Munnix ICA, Gilio K, Siljander PRM, et al. Collagen-mimetic peptides mediate flow-dependent thrombus formation by high- or low-affinity binding of integrin alpha2betal and glycoprotein VI. J Thromb Haemost 2008; 6: 2132-2142.

9. Rink TJ, Sage SO. Calcium signaling in human platelets. Annu Rev Physiol 1990; 52: 431-449.

10. Jackson SP, Nesbitt WS, Kulkarni S. Signaling events underlying thrombus formation. J Thromb Haemost 2003; 1: 1602-1612.

11. Varga-Szabo D, Braun A, Nieswandt B. Calcium signaling in platelets. J Thromb Haemost 2009; 7: 1057-1066.

12. Kuwahara M, Sugimoto M, Tsuji S, et al. Cytosolic calcium changes in a process of platelet adhesion and cohesion on a von Willebrand factor-coated surface under flow conditions. Blood 1999; 94: 1149-1155.

13. Mazzucato M, Pradella P, Cozzi MR, et al. Sequential cytoplasmic calcium signals in a 2-stage platelet activation process induced by the glycoprotein Ibalpha mechanoreceptor. Blood 2002; 100: 2793-2800.

14. Nesbitt WS, Kulkarni S, Giuliano S, et al. Distinct glycoprotein Ib/V/IX and integrin alpha IIbbeta 3-dependent calcium signals cooperatively regulate platelet adhesion under flow. J Biol Chem 2002; 277: 2965-2972.

15. Goncalves I, Hughan SC, Schoenwaelder SM, et al. Integrin alpha IIb beta 3-dependent calcium signals regulate platelet-fibrinogen interactions under flow. Involvement of phospholipase C gamma 2. J Biol Chem 2003; 278: 34812-34822.

16. Nesbitt WS, Giuliano S, Kulkarni S, et al. Intercellular calcium communication regulates platelet aggregation and thrombus growth. J Cell Biol 2003; 160: 1151-1161.

17. Mazzucato M, Cozzi MR, Pradella P, et al. Distinct roles of ADP receptors in von Willebrand factor-mediated platelet signaling and activation under high flow. Blood 2004; 104: 3221-3227.

18. Auger JM, Kuijpers MJE, Senis YA, et al. Adhesion of human and mouse platelets to collagen under shear: a unifying model. FASEB J Off Publ Fed Am Soc Exp Biol 2005; 19: 825-827.

19. Goto S, Tamura N, Ishida H, Ruggeri ZM. Dependence of platelet thrombus stability on sustained glycoprotein IIb/IIIa activation through adenosine 5'-diphosphate receptor stimulation and cyclic calcium signaling. J Am Coll Cardiol 2006; 47: 155-162.

20. Mazzucato M, Cozzi MR, Battiston M, et al. Distinct spatio-temporal Ca2+ signaling elicited by integrin alpha2betal and glycoprotein VI under flow. Blood 2009; 114: 2793-2801. 
21. Ikeda Y, Handa M, Kamata T, et al. Transmembrane calcium influx associated with von Willebrand factor binding to GP Ib in the initiation of shear-induced platelet aggregation. Thromb Haemost 1993; 69: 496-502.

22. Savage B, Saldivar E, Ruggeri ZM. Initiation of platelet adhesion by arrest onto fibrinogen or translocation on von Willebrand factor. Cell 1996; 84: 289-297.

23. Yap CL, Hughan SC, Cranmer SL, et al. Synergistic adhesive interactions and signaling mechanisms operating between platelet glycoprotein Ib/IX and integrin alpha IIbbeta 3. Studies in human platelets ans transfected Chinese hamster ovary cells. J Biol Chem 2000; 275: 41377-41388.

24. Pugh N, Bihan D, Perry DJ, Farndale RW. Dynamic analysis of platelet deposition to resolve platelet adhesion receptor activity in whole blood at arterial shear rate. Platelets 2015; 26: 216-219.

25. Watson B, White N, Taylor K, et al. Zinc is a Transmembrane Agonist that In duces Platelet Activation in a Tyrosine Phosphorylation-Dependent Manner. Metallomics 2016; 8: 91-100.

26. Jennings LK. Mechanisms of platelet activation: need for new strategies to protect against platelet-mediated atherothrombosis. Thromb Haemost 2009; 102: 248-257.

27. Zhang K, Chen J. The regulation of integrin function by divalent cations. Cell Adhes Migr 2012; 6: 20-29.

28. Jen CJ, Chen HI, Lai KC, Usami S. Changes in cytosolic calcium concentrations and cell morphology in single platelets adhered to fibrinogen-coated surface under flow. Blood 1996; 87: 3775-3782.

29. Yuan Y, Kulkarni S, Ulsemer P, et al. The von Willebrand factor-glycoprotein Ib/ $\mathrm{V} / \mathrm{IX}$ interaction induces actin polymerization and cytoskeletal reorganization in rolling platelets and glycoprotein Ib/V/IX-transfected cells. J Biol Chem 1999; 274: 36241-36251.

30. Kuijpers MJE, Schulte V, Bergmeier W, et al. Complementary roles of glycoprotein VI and alpha2betal integrin in collagen-induced thrombus formation in flowing whole blood ex vivo. FASEB J Off Publ Fed Am Soc Exp Biol 2003; 17: 685-687.
31. Quinton TM, Dean WL. Cyclic AMP-dependent phosphorylation of the inositol-1,4,5-trisphosphate receptor inhibits $\mathrm{Ca} 2+$ release from platelet membranes. Biochem Biophys Res Commun 1992; 184: 893-899.

32. Mahaut-Smith MP. The unique contribution of ion channels to platelet and megakaryocyte function. J Thromb Haemost 2012; 10: 1722-1732.

33. Barstad RM, Orvim U, Hamers MJ, et al. Reduced effect of aspirin on thrombus formation at high shear and disturbed laminar blood flow. Thromb Haemost 1996; 75: 827-832.

34. Maloney SF, Brass LF, Diamond SL. P2Y12 or P2Y1 inhibitors reduce platelet deposition in a microfluidic model of thrombosis while apyrase lacks efficacy under flow conditions. Integr Biol Quant Biosci Nano Macro 2010; 2: 183-192.

35. Mendolicchio GL, Zavalloni D, Bacci M, et al. Variable effect of P2Y12 inhibition on platelet thrombus volume in flowing blood. J Thromb Haemost 2011; 9: 373-382.

36. Cosemans JMEM, Iserbyt BF, Deckmyn H, Heemskerk JWM. Multiple ways to switch platelet integrins on and off. J Thromb Haemost 2008; 6: 1253-1261.

37. Cruz MA, Chen J, Whitelock JL, et al. The platelet glycoprotein Ib-von Willebrand factor interaction activates the collagen receptor alpha2betal to bind collagen: activation-dependent conformational change of the alpha2-I domain. Blood 2005; 105: 1986-1991.

38. Arya M, López JA, Romo GM, et al. Glycoprotein Ib-IX-mediated activation of integrin alpha(IIb)beta(3): effects of receptor clustering and von Willebrand factor adhesion. J Thromb Haemost 2003; 1: 1150-1157.

39. Jung SM, Moroi M. Platelet collagen receptor integrin alpha2beta1 activation involves differential participation of ADP-receptor subtypes P2Y1 and P2Y12 but not intracellular calcium change. Eur J Biochem FEBS 2001; 268: 3513-3522.

40. Hardy AR, Jones ML, Mundell SJ, Poole AW. Reciprocal cross-talk between P2Y1 and P2Y12 receptors at the level of calcium signaling in human platelets. Blood 2004; 104: 1745-1752.

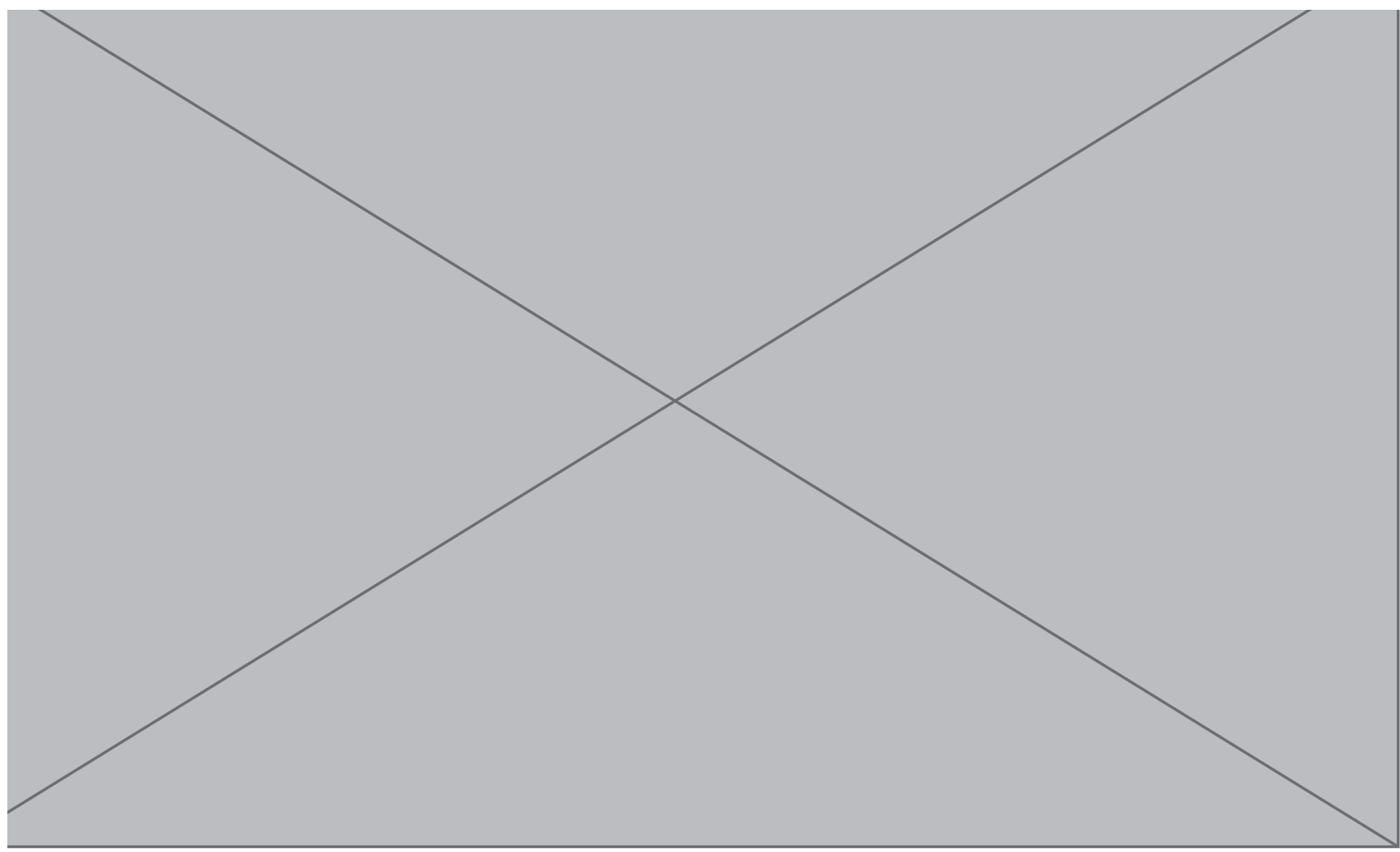

